\title{
Late presentation of polyvinyl alcohol sponge (Ivalon) aortic graft failure
}

\author{
PAULA H B BOLTON-MAGGS AND ROGER W MOTSON \\ From the Departments of Medicine and Surgery, Norfolk and Norwich Hospital, \\ Norwich, Norfolk, UK
}

Surgical repair has radically improved the outlook of patients with coarctation of the aorta. In some cases a long stenotic segment makes end-to-end anastomosis impossible, and a graft must be used to bridge the gap. In the 1950s aortic homografts and a wide variety of synthetic materials were used, and we report the late complications of one such case. It is interesting because stenosis recurred at the sites of anastomosis of the graft to the aorta, with loss of the distal pulses but without the recurrence of pronounced hypertension, and because a false aneurysm around the graft ruptured 22 years after insertion.

\section{Case report}

A 20-year-old woman was found to have hypertension $(160 / 100 \mathrm{mmHg})$ during a pregnancy in 1955 . A diagnosis of coarctation of the aorta was confirmed and at operation in 1956 the coarctation was found to begin $2.5 \mathrm{~cm}$ below the origin of the left subclavian artery and to extend $5 \mathrm{~cm}$ distally. After excision of the stenotic segment continuity was restored with an Ivalon graft, end-to-end anastomosis being impossible. Recovery was uneventful, and the blood pressure fell to $150 / 80 \mathrm{mmHg}$.

Her hypertension recurred in 1969 when she was taking an oral contraceptive but returned to normal when this was discontinued. The physical signs, however, suggested stenosis or occlusion of the graft, and aortography in 1974 showed stenosis at the junction between the distal end of the graft and the aorta. In the absence of hypertension or symptoms no further treatment was prescribed.

In 1977, now aged 42, she had a haemoptysis of $500 \mathrm{ml}$ of bright red blood, accompanied by cyanosis, dyspnoea, and shock. The haemoglobin fell by $2 \mathrm{~g} / \mathrm{dl}$ to $10.5 \mathrm{~g} / \mathrm{dl}$. An arch aortogram showed little change in appearance from 1974 (fig 1). After a second episode of severe haemoptysis a left thoracotomy was performed. The lung appeared normal but the posterior surface of the upper lobe was firmly adherent to a false aneurysmal sac, which was the source of the haemoptyses. The Ivalon graft was lying free within the sac, and there was clotted blood in its lumen. There was no evidence of the graft ever having been incorporated into the surrounding tissues (fig 2). There was stenosis of the aorta at the sites of previous anastomosis. The graft and stenotic aortic segments were removed and replaced by a Dacron graft. Recovery was uneventful.

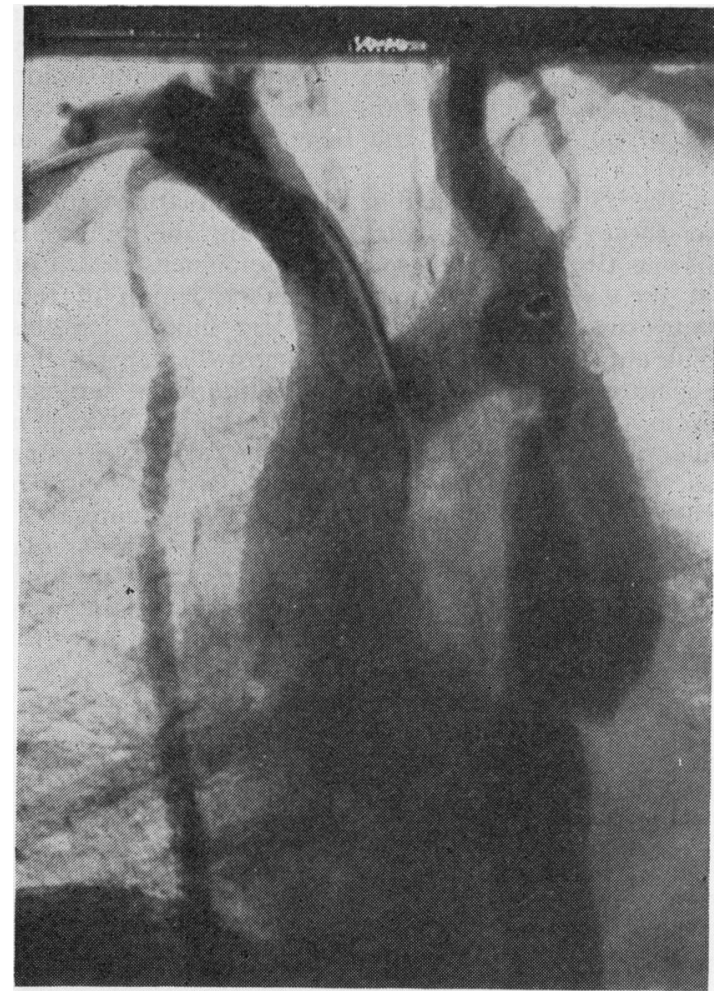

Fig 1 Arch aortogram, anteroposterior view. Ascending aorta is dilated, descending aorta is stenosed above and below aneurysmal segment. Graft is lying obliquely in aneurysmal cavity, and medial edge can be seen as a white line.

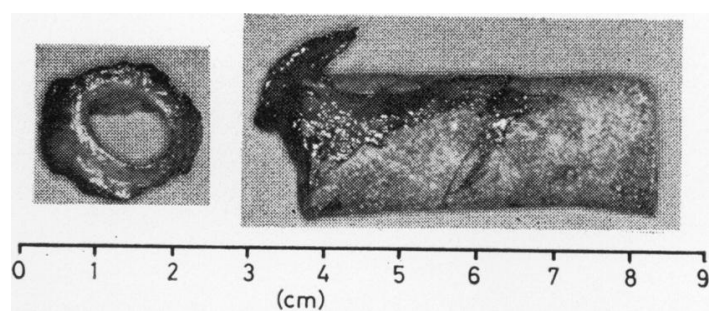

Fig 2 Polyvinyl alcohol sponge graft after removal. Blood clot protrudes from graft. On left is one of stenosed segments of aorta. 


\section{Discussion}

Ivalon, a polyvinyl alcohol sponge hardened with formaldehyde, was one of several synthetic arterial graft materials used in the 1950 s. Several properties accounted for its early popularity including malleability (enabling a wide variety of shapes and sizes of graft to be prepared), ease of handling at operation, high tensile strength, and easy ingrowth of fibrous tissue. Early reports were encouraging, and it was considered favourably in a comprehensive review by Rob et al (1955-6). Subsequent experience, however, showed difficulties in manufacture and, more seriously, a tendency in vivo to loss of tensile strength, failure of fibrous tissue ingrowth, calcification, and in some cases rupture (Brown and Essig, 1959; Sauvage et al, 1967).

The failure reported here showed features similar to those of earlier dates, including the failure of fibrous tissue ingrowth, but the development of stenosis at the sites of anastomosis and the length of time between insertion and rupture are unique features. The almost total lack of tissue ingrowth suggests that separation of the graft occurred quite early, probably from a haematoma resulting from a tear or leakage at the suture line. Development of a false aneurysmal sac concealed the symptoms until partial rupture of the sac lead to her presentation with haemoptyses.

Ivalon has long since been abandoned as a vascular graft. However, graft failure that remains asymptomatic for many years after operation raises wider issues with regard to the long-term fate of all currently used prosthetic materials. Recently, attention has been drawn to the lack of data concerning this, and the incidence of graft failure may be higher than reporting suggests (Ottinger et al, 1976; Blumenberg and Gelfand, 1977). Clearly, it is important to keep all patients with synthetic grafts under long-term review and to report any failures to the manufacturers.

We thank Mr A B Birt and Dr W Oliver for allowing us to report on this patient who was under their care.

\section{References}

Blumenberg, R M, and Gelfand, M L (1977). Failure of knitted Dacron as an arterial prosthesis. Surgery, 81, 493-496.

Brown, L, and Essig, H (1959). Fatal rupture of an Ivalon (polyvinyl formalinized) sponge aortic graft into duodenum. Archives of Surgery, 79, 72-74.

Ottinger, L W, Darling, R C, Wirthlin, L S, and co Linton, $R \quad R$ (1976). Failure of ultralightweight कs knitted Dacron grafts in arterial reconstruction. Archives of Surgery, 111, 146-149.

Rob, C G, Eastcott, H H G, and Owen, K (1955-6). The reconstruction of arteries. British Journal of Surgery, 43, 449-466.

Sauvage, L R, Berger, K E, and Gross, R E (1967). Long-term fate of compressed Ivalon as a cardiovascular graft. Annals of Surgery, 166, 844-851.

Requests for reprints to: Roger W Motson, FRCS, The London Hospital, London E1 1BB. 